\title{
Effect of COVID-19 Pandemic on Consumption Patterns among Egyptian Consumers and Its Relation to Maslow's Hierarchy of Needs
}

\author{
Amal Seddik Afify \\ Thebes Academy, Cairo, Egypt \\ Email: Amalsafify@yahoo.com
}

How to cite this paper: Afify, A. S. (2022). Effect of COVID-19 Pandemic on Consumption Patterns among Egyptian Consumers and Its Relation to Maslow's Hierarchy of Needs. Modern Economy, 13, 186-207.

https://doi.org/10.4236/me.2022.132012

Received: December 22, 2021

Accepted: February 22, 2022

Published: February 25, 2022

Copyright $\odot 2022$ by author(s) and Scientific Research Publishing Inc. This work is licensed under the Creative Commons Attribution International License (CC BY 4.0).

http://creativecommons.org/licenses/by/4.0/

\begin{abstract}
This research work studies changes in the behavior of Egyptian consumers initiated during the Coronavirus pandemic crisis. It aims to examine the extent of change in consumption patterns among various categories, in an attempt to arrive at a pattern or map that reflects buying motivations as well as to identify whether new needs have emerged that can be added to Maslow's hierarchy of needs. This research work adopted a preparatory desk study to formulate the research propositions and guide the preparation of a survey questionnaire list to cover all aspects of the research. The researcher then carried out a preliminary test of the survey list and modified it in light of the results. The researcher thus placed the modified survey questionnaire on the Internet, receiving 400 random responses from different categories and sectors. The researcher did a quantitative count of responses then performed statistical analysis and correlation tests to detect any compatibilities or relations, if present, between responses and categories. The study aimed to identify the most changed behaviors in Egypt within and outside Greater Cairo. The researcher found that behavior of all the sample members changed following the pandemic, and that they have become more anxious about the future.
\end{abstract}

\section{Keywords}

Marketing, Consumer Behavior, Egyptian Consumption Patterns, Maslow's Hierarchy of Needs, Buying Motivations

\section{Introduction}

As if we all walked into a sci-fi movie, COVID-19 virus has transformed the world as we know it. In just a few weeks, the virus broke out in many countries 
across the globe. A creature too small to be seen by the naked eye took over the whole world: confining people to their homes and closing stores, company offices and factories. Above all, a real change ensued in people's behaviors, habits, and shopping means and methods, perhaps conceivably even in their way of thinking. Coronavirus brought about an actual test of the reselience of international chains, a boom in online shopping, a change in people's buying priorities, and the emergence of totally new consumption patterns in local and global markets. A need thus arises to reassess theories on consumer buying behavior, especially under crisis. What are the buying motivations? Do they get altered under crisis? Or do buying motivations change over time and crises play the mere role of highlighting that change?

Consumer buying behavior under crisis is not adequately, dealt with. There is a stark need to analyze buying behavior in crisis time. Such gap can be tackled empirically in this current research.

This study aims to examine the change in Egyptian consumer behavior accompanying the Coronavirus pandemic crisis, and the degree of variance in consumer patterns in the different social categories in an attempt to reach a pattern or map reflecting buying motivations in crisis time. This, I hope, will fill a gap in consumer theory.

\subsection{Research Topic and Significance}

The COVID-19 pandemic has led to world-wide economic and social changes, with social distancing causing unprecedented social and psychological effects. Coronavirus and its repercussions have prompted developing new methods in crisis management and resorting to financial planning at both individual and societal levels in order to cope with unprecedented circumstances that have altered people's behavior, interests, buying habits and consumption patterns. The unfamiliar conditions led some to consume more, some to save more. Moreover, new habits began to develop as a result, such as a passion for the latest technologies and digital communication methods; excessive storage of goods in fear of their going out of stock; and, for many, replacing direct face-to-face shopping with buying via the Internet and delivery. Also interest in home entertainment goods rose while restaurant and coffee shop outings dropped due to imposed reduction of their opening hours.

This study investigates the nature and extent of change in consumer patterns as affected by the new COVID-19 pandemic as a model of crises with direct effects on individuals' lives and buying preferences; explores whether a permanent change in buying priorities has been revealed by the crisis; and discusses the relationship between needs' theories, particularly Maslow's hierarchy of needs, and buying motivations. It also examines whether new motivations have developed, requiring an addition of a new level of needs, which would necessarily influence our understanding of consumer buying motivations hence have a strong impact on finding new marketing opportunities for corporations and investment entities to keep pace with the change in consumer trends and consumption patterns. 


\subsection{Research Proposals}

This study aims to investigate the following propositions:

1) Consumer behavior has changed following the Coronavirus pandemic.

2) Needs theories explain consumer behavior.

3) A new level of needs has developed and must be taken into consideration and included in existing needs' theories.

\subsection{Research Methodology}

This research work adopted a preparatory desk study to formulate the research propositions and guide the preparation of a survey questionnaire list to cover all aspects of the research. The researcher then carried out a preliminary test of the survey list through distributing 20 printed copies to individuals and modifying the list in light of the test results for greater clarity of questions and accuracy of answers. Since the study population is unlimited size, and the geographical divergence of its units furthermore, it has no frame, the researcher used Steven Thompson's formula (Thompson, 2012) with 95\% confidence and a margin of error 0.05 , to calculate the sample size. That is,

$$
\begin{aligned}
n & =\frac{z^{2} \times p(1-p)}{\alpha^{2}} \\
& =\frac{1.96^{2} \times 0.5(1-0.5)}{0.05^{2}} \\
& \approx 384
\end{aligned}
$$

The researcher thus placed the modified survey questionnaire on the Internet, receiving 376 random responses from different categories and sectors. The researcher did a quantitative count of responses then performed statistical analysis and correlation tests to detect any compatibilities or relations, if present, between responses and categories.

\subsection{Main Research Elements}

This study consists of three main sections. The first section is introductory, the second part consists of the theoretical background and the third is the main findings of the paper.

The theoretical background consists of three main parts titled "Coronavirus pandemic as a global and local crisis", "Consumer behavior change as a result of COVID-19 pandemic" and "Needs' theories and their relation with buying motivations and consumption patterns". The next section discusses the main findings of the research describing the consumption patterns of Egyptians, impact of COVID-19 on them and the emergence of new needs. Finally, the article discusses the relationship between demographic variables and consumption and then ends with a section presenting results and recommendations.

\section{Theoretical Background}

Being a fairly new pandemic the researcher will devote the following lines to de- 
scribing the picture after COVID-19 emergence, in addition to a brief summary of the needs theory and how its relation to buying motivations and consumption patterns.

\subsection{Coronavirus Pandemic as a Global and Local Crisis}

The economic effects of the pandemic are globally evident. It led to an interconnected circle, starting with a decrease in incomes, which negatively affected consumption rates, in turn reflecting on a decrease of production that led to more layoffs of workers or at least a lowering of wages and salaries, which led to a further decrease in consumption hence in production (Funakoshi \& Hartman, 2020).

The pandemic has led to a slowing-down or a complete halt in several sectors, such as tourism, aviation, restaurants and function halls; a decrease in incomes of institutions operating in the industry as well as wholesale and retail trade fields; and postponement of investment decisions and a reduction of business volume for numerous corporations. This has led to cutbacks in hiring, layoffs and reduction of staffing structure growth rates. Income shrinkages have ensued, causing increased anxiety about the future even among those whose incomes were not affected. At the collective level, all this resulted in a tendency to save and, for many items, a decrease in consumption, while for other items, an unprecedented increase in consumption in the form of panic purchasing driven by anxiety about the future.

Moreover, the lockdown and reduction of transportation in most countries caused a severe drop in oil prices ${ }^{1}$, which affected the economy and purchasing power of producing countries, thus negatively affecting world trade traffic (Kotishwar, 2020). Recent official data indicated that total losses in Egyptian economy alone, due to the crisis related to the implications and risks of the spread of the new Coronavirus, reached nearly 105 billion Egyptian pounds (Abdulhameed, 2020).

In the Middle East and North Africa in particular, the negative consequences of Covid-19 pandemic on the economy, the national product, and the average per capita share of it are evident. There has been a decrease in oil prices and in growth rates of internal and external trade; disturbances have occurred in the region; and a deterioration resulted in the Gross Domestic Product (GDP). However, there is a disparity among countries, Libya and Lebanon being the most and Egypt the least affected. The following diagram indicates the change in GDP in Middle East countries as percentages (OECD, 2020) (Figure 1).

World Bank reports indicate an attempt of the various countries to contain the Coronavirus crisis and mitigate its effects on their peoples (Gentilini et al., 2020). The following diagram shows the increasing number of countries that have implemented social programs to help individuals cope with the crisis during the period from March to May 2020, which started with 45 nations providing social aid to their citizens and ended with 181 nations providing it, which indicates deteriorating economic conditions of consumers worldwide and their need for help (Figure 2).

\footnotetext{
${ }^{1}$ Oil prices dropped from $\$ 52$ to approximately $\$ 45$ per barrel.
} 


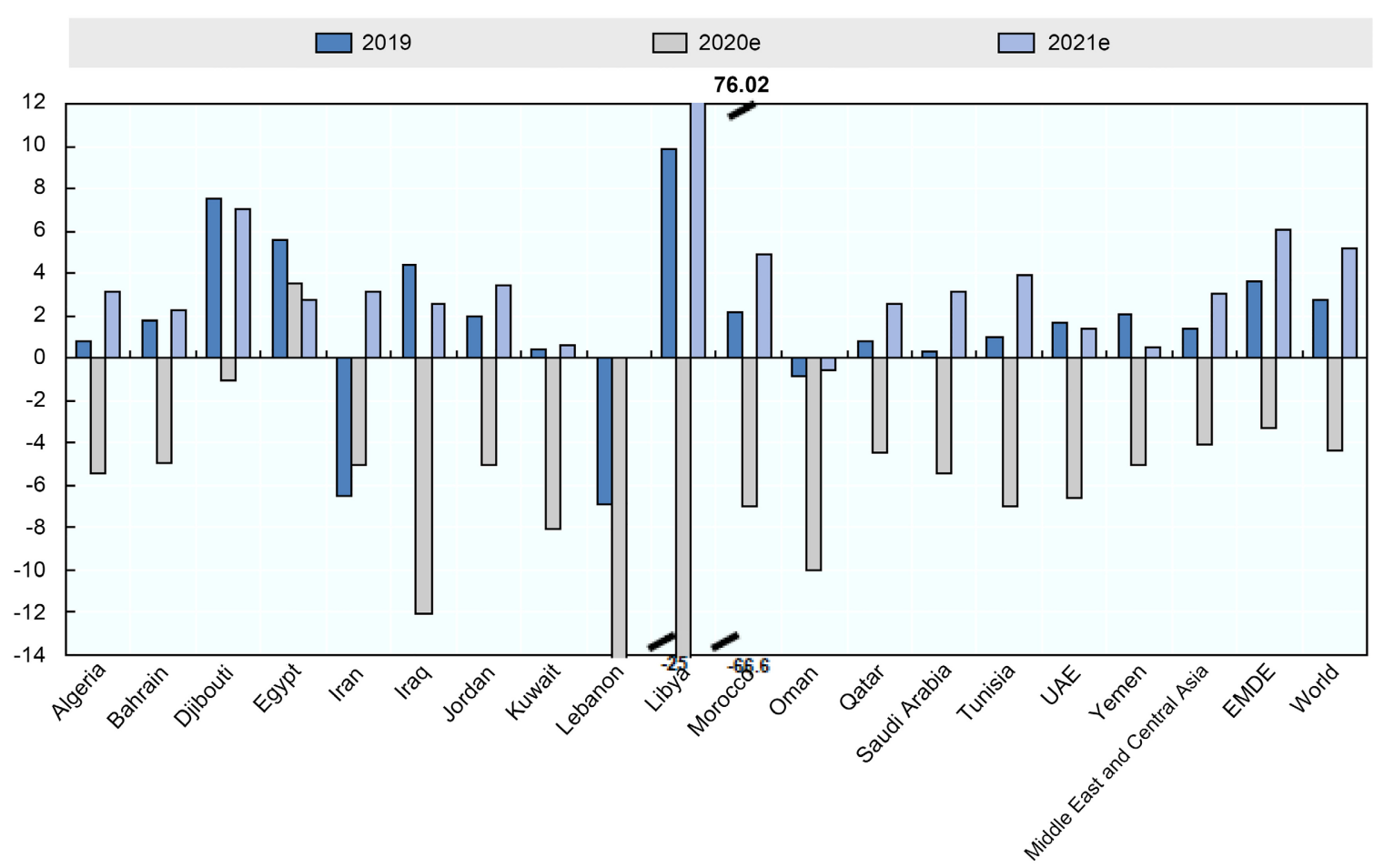

Figure 1. GDP in economies of Middle East and select North Africa countries (change in annual percentage). e = estimates; EMDE = Emerging Markets and Developing Economies. Source: International Monetary Fund (IMF), World Economic Outlook Database, October 2020.

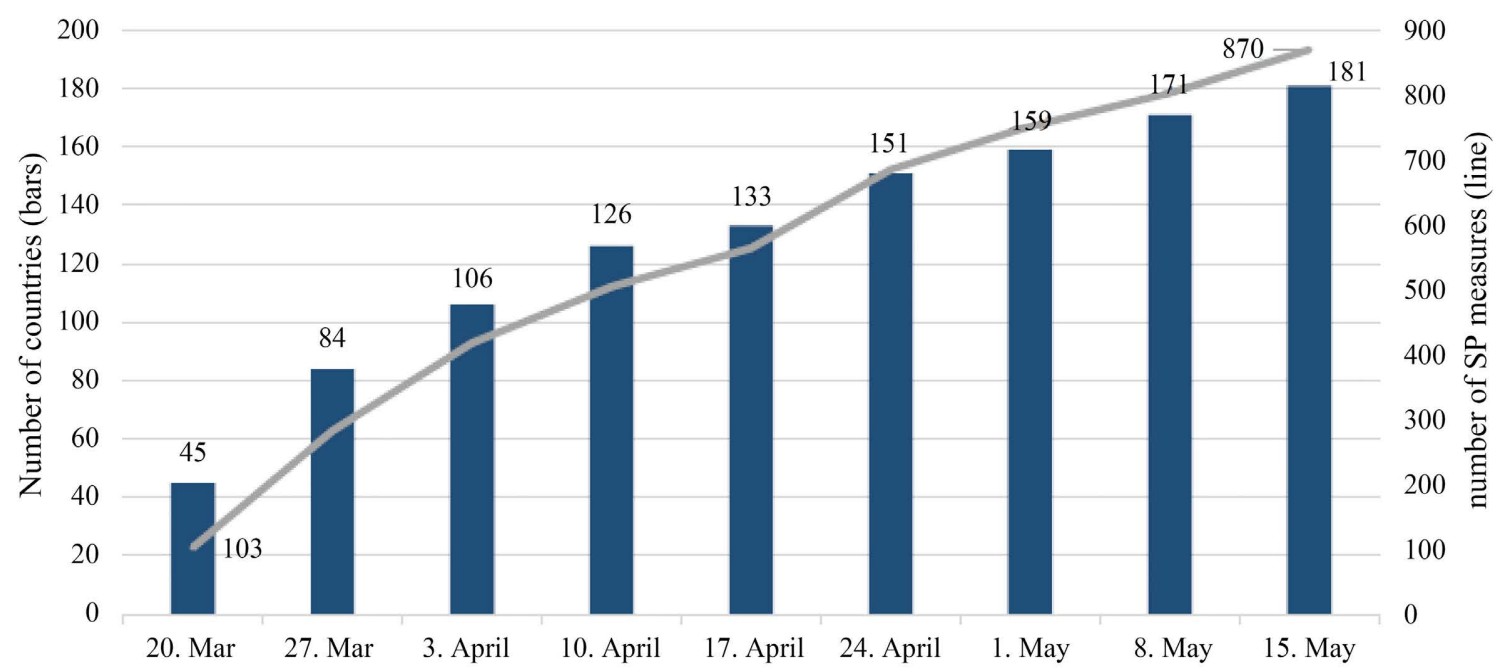

Figure 2. Number of countries and districts (bars) and social protection measures (line) (20 March-15 May 2020). Source: International Monetary Fund (IMF), World Economic Outlook Database, October 2020.

\subsection{Consumer Behavior Change as a Result of COVID-19 Pandemic}

Income decrease due to the Coronavirus spread has led to a general change in consumers' behavior, purchasing habits and economic decisions all over the world (Puttaiah et al., 2020). Consumers' tendency to buy and store some goods has increased as a result of fear they may not be available in future, while there has been a decrease in many habits such as frequenting restaurants and cafes, 
and buying famous brands or non-essential goods and latest electronic and durable goods. Income decrease among wide categories has led to consumers' disinclination to make long-term investments such as real estate and land, causing a decrease in demand for them and consequently for related industries, hence a decline in their sales and prices.

A recent report by a famous American-Irish organization in the marketing field identified five consumer archetypes according to the extent of behavior change following the Coronavirus pandemic (Accenture, 2020). The Worrier (21\%) is consumed by fear and anxiety of the pandemic's impact, follows the news carefully, is willing to adopt any precautionary measure to protect themselves against the virus, is mostly in the old-age group, and shows a $50 \%$ decrease in consumption for preventive goods. The Individualist (22\%) is concerned with their personal safety and that of their family but not much interest in others, is more resistant to follow any governmental precautionary measures, does not invest much in preventive goods so long as they feel danger is not near. The Rationalist (39\%) has come to take the virus risk very seriously, follows the news, adheres to precautionary measures and instructions and buys everything related to it. The Activist (8\%) not only buys preventive goods needed by their family but extends their activities to the community and attempts to spread health awareness and distribute precautionary products to others. Finally, the Indifferent (11\%) who sees the whole subject over-rated, ignoring facts and continuing to live life normally as usual, is generally less anxious and anticipatory than the other types. According to this study, most sample members turned their attention toward buying basic needs and away from commodities that are complementary or related to higher needs.

\subsection{Needs Theories and Their Relation with Buying Motivations and Consumption Patterns}

Needs theories were developed to explain human behavior and have evolved regularly since the late nineteenth century, from James (1890), (Allport, 1937, 1961), (Maslow, 1943, 1970a), (Herzberg, 1966), (Alderfer, 1971) to (Lowry and Maslow, 1979).

William James was the first to classify human needs into basic, social and psychological needs. He divided the human self into three categories: the "Me" that deals with physiological needs such as food, clothing and shelter; the social "Me" that is concerned with status and how others see the person; and the upper "Me" that deals with internal motives such as interests, beliefs and spiritualities that drive the self toward specific actions, that is, it is the main link between outward behavior and internal psychological needs (James, 1890). If we apply this theory to buying motives, we will find that they are divided into three groups: a group of motives related to physiological needs and what a person needs in order to survive; another group of motives related to a person's image as perceived by others, which drives one to a desire to boast, thus prompting them to own items such as precious jewelry, luxury cars and luxurious homes; 
and finally a third group of motives related to psychological needs and leading to one's pursuit of internal comfort such as buying charitable bonds in orphanage.

Allport (1961) focused on the growth of the self and the development of the personality and its needs, stressing that needs are created with the child and grow with the person, even if it seems that the link between one's present and past is severed in the stage of maturity. Needs are formed from as early as a person's birth like a seed that sprouts, grows and is affected by the different surrounding circumstances, which is reflected in a person's interests and actions hence on their buying motives. We find a child's desires and buying motives revolve around instant gratification, such as candy or toys, while after maturity, buying motives change to become more consistent with a person's circumstances and ambitions for the future, such as investing in real estate.

Maslow's theory of needs (Maslow, 1970a) is the most used psychology theory in explaining human motives and needs. It has applications in management sciences, motivating employees, buying motivations and marketing sciences.

Maslow divided human needs into five levels, whereby a person does not move from one level to a higher one until the previous level has been satisfied. He started with the physiological needs of food, clothing and shelter as the lowest level that must be satisfied, then moved to the need for security and safety, which is concerned with securing the place in addition to securing the future as a motive that explains human behavior. At the third level he put social needs such as the need to belong to a group and thus to the workplace or a specific band. $\mathrm{He}$ defined the fourth level as the need for esteem and respect and as a fundamental driver directing human behavior. At the highest level of human motives he put self-actualization (McLeod, 2020).

Maslow arranged these needs in a hierarchical pyramid shape with physiological needs at the base while the remaining needs are on top of each other up to the top of the pyramid's triangle where there are needs of self-actualization and realization of the true self. According to this division, human needs are divided into two main groups: what an individual possesses, which comprises the first four levels; and the individual's being, which is the fifth level.

There was some disagreement with Maslow on the necessity to satisfy one level of needs separately then move to the higher level. Some believed that more than one need could be addressed at the same time, including Revich (2005), who divided needs into three fundamental groups that overlap most of the time. Revich (2005) showed the relation between those three groups and Maslow's hierarchy in the following diagram. Security needs include the physiological and safety needs mentioned by Maslow, while the two needs of esteem and selfactualization are represented by the status and stimulation needs. As for the need for belonging, it is represented in the three groups, which in turn overlap with one other (Figure 3).

Lowry \& Maslow (1979) modified his hierarchy pyramid to contain seven levels, as he realized that self-actualization should be further divided. He thus added two new levels preceding the final self-actualization, one for cognitive 


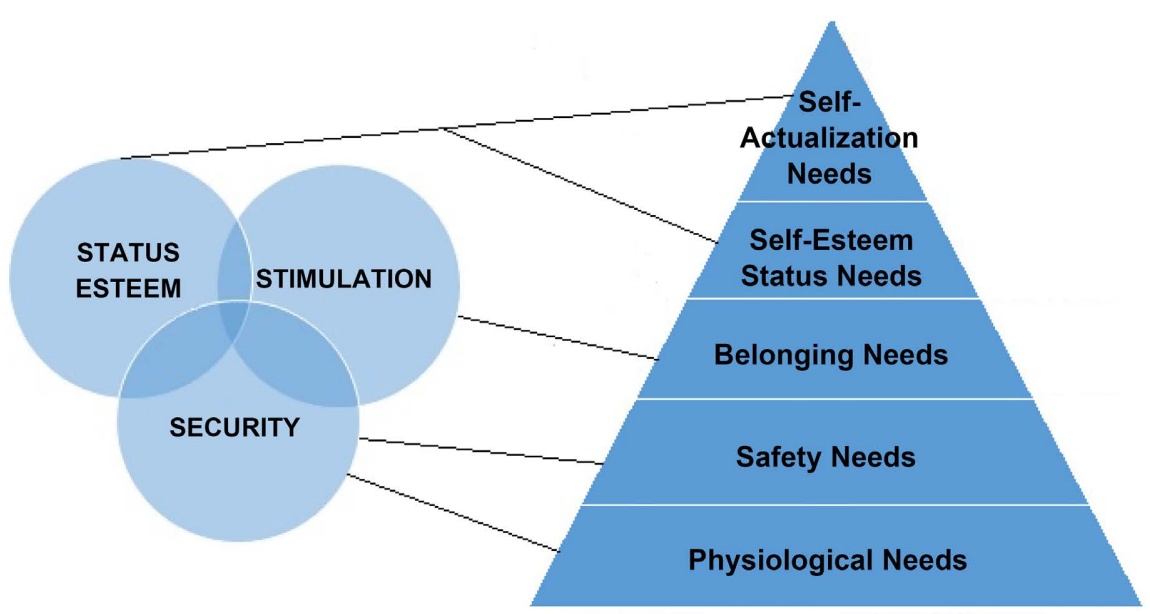

Figure 3. The relation between Maslow's needs and Revich's three fundamental needs groups (2005). Source: Revich (2005) “The Three Fundamental Needs model”, from: https://www.workitout.ca/.

needs such as the desire for learning and exploration (level five), and another for aesthetic needs, related to appreciation of beauty, balance, etc. (level six), and kept self-actualization at the top of the hierarchy (level seven) Maslow (1970a).

This same study (Lowry and Maslow, 1979) also modified the physiological needs concept so that it is not limited to survival requirements such as water and food, but has come to include physical activities such as sleep, warmth and the need for reproduction, etc. Safety needs were similarly modified to include the need for law and order to complete the feeling of safety and security.

This modified, seven-level hierarchy enabled grouping of needs into two major groups, the first comprising the lower four levels, covering what a person owns, and the second comprising the top three levels concerning a person's being, which reflects the human concern with higher needs such as need for learning, aesthetics and self-actualization.

Maslow then added an eighth level on top, naming it Transcendence, which is concerned with needs that transcend beyond the person's self, such as helping others and beliefs (Maslow, 1970b). Maslow concluded that after realizing oneself and reaching one's best image, a person begins to search for non-sensory values to transcend one's self and elevate it above daily needs, thus emerges a new need for mental clarity, transcendence and elevation above self, through spiritual values, balance activities such as yoga and meditation, and religious rituals (Figure 4).

Studies followed linking Maslow's research with management sciences (Figure 4), using it to explain the behavior of employees and motivate them, but Kotler was one of the first to apply the Maslow hierarchy, to sort human needs in order to explain consumer behavior, needs and preferences that explain their purchasing priorities and influence them (Kotler and Keller, 2006). Kotler considered the market to be a consumer's surrounding environment, which is equivalent to organizations for employees, and that a good marketer must understand 


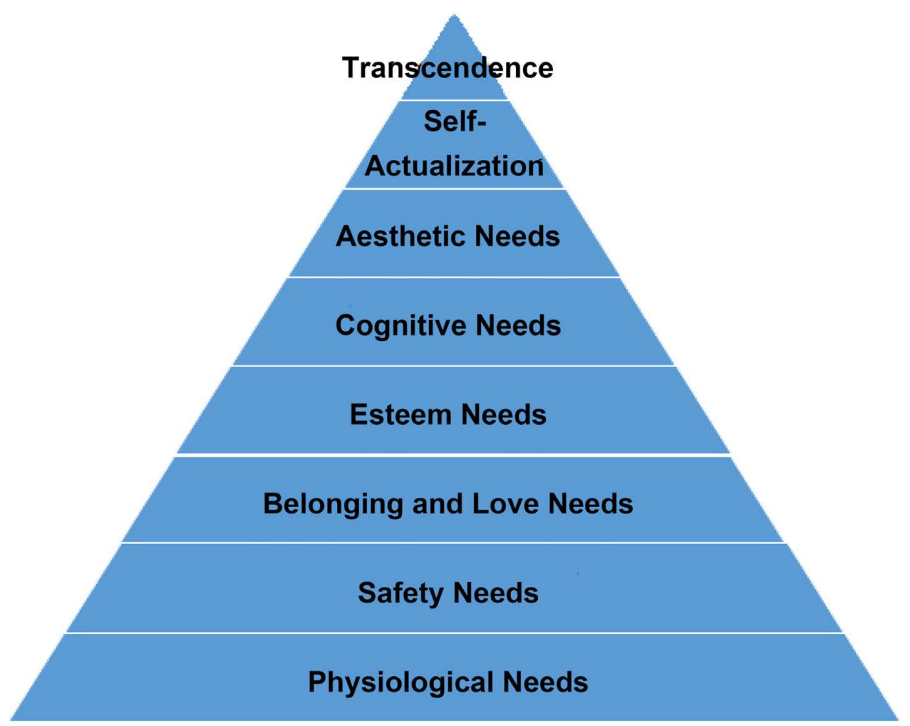

Figure 4. Maslow's hierarchy of needs after addition of three levels. Source: Maslow (1970b). Religions, values, and peak experiences. New York: Penguin (Original work published 1966).

consumers and their needs, whether five or seven, in order for the marketer to satisfy their current and future needs and attract them to buy the marketed commodity.

Physiological needs dictate that producers manufacture food, housing, clothing and therapeutic products to cover consumers' basic needs. Consumers' safety needs prompt establishing security companies and factories for surveillance cameras to protect against theft; create the need for life and health insurance companies as well as insurance against accidents, disasters and fires; increase the importance of factories manufacturing vitamins, tonics, and goods for prevention against disease such as vaccines and disinfectants; and result in early warning systems for hazards such as earthquakes and fires.

The need for belonging is reflected in consumers' interest in brands and marketers' efforts to create loyalty to a product's name in addition to fostering establishment of sports clubs. Esteem needs are reflected in buying expensive products, such as palaces, luxury cars, gold and diamonds; and in holding lavish parties and celebrations. As for the need for self-actualization, this is reflected in the desire for realization through attaining success in a certain career or study or achieving a goal or accomplishment, and is reflected marketing-wise in private universities' services and competitions.

As Maslow added two more levels to his hierarchy of needs, new buying motives were detected. The cognitive level concerned with learning introduced the demand for new services such as additional educational programs, training courses and workshops, and human-development and self-development lectures. The other new level related to aesthetics and balance brought up the demand for everything that can add beauty to people and places, such as fancy clothes, expensive accessories, and complementary furniture, lights and decoration. It also 
is reflected in the increased demand for mental and emotional clarity programs and spas, yoga and meditation, sports training venues, etc.

Some World Food Organization studies show a relationship between the level of income and the hierarchy of needs, finding that the higher an individual's income, the less their spending is on physiological and safety needs, and the more on goods that satisfy higher needs such as belonging, esteem and self-actualization (Ward and Lasen, 2009).

A well-known needs theory is Herzberg's theory, in which he divided factors affecting individuals in an organization into motivational factors that drive workers to improve their performance and normal factors that do not directly motivate them yet absence of these factors would negatively affect performance (Herzberg, 1966). Linking this to buying motives, we can identify factors that motivate consumers to buy, such as the degree of benefit from a commodity, its quality and its catchy appearance; and other factors that do not promote the purchase yet their absence would negatively affect the decision to buy, such as the commodity's intactness and its conformity with the industry's standards.

Following Kotler, several authors attempted to explain buying behavior through needs theories, with the aim of finding patterns that help producers meet consumer needs and attract them to buy. Among them were Ward and Lasen (2009), who conducted a comparative study between different needs theories and linked them to consumer behavior, stating that all human needs present marketing opportunities and that three types of marketing opportunities can be addressed, namely individual needs, institutional needs, and company needs. This requires identifying the needs of individuals and societies and re-examining them as regards priorities for the individual, society and the environment, in order to verify that the needs that are satisfied are in line with the interest of individuals and societies as well as moral values.

\section{Findings of the Research}

The following are the main findings of the research:

\subsection{Consumption Patterns of Egyptians}

The researcher conducted a survey with the aim of finding out how consumers' behavior has changed as a result of the pandemic and how that affected their consumption patterns and spending behavior.

\subsubsection{Consumer Behavior Changes}

The researcher conducted a survey to identify the most changed behaviors in Egypt within and outside Greater Cairo. She found that behavior of all the sample members changed following the pandemic, and that they have become more anxious about the future. About eighty of the sample expressed their fear of the future through answers that vary between confirming their fear of the future strongly and fearing it to some degree. Also, about $66 \%$ indicated that they have become more inclined to save after the pandemic (Figure 5). 


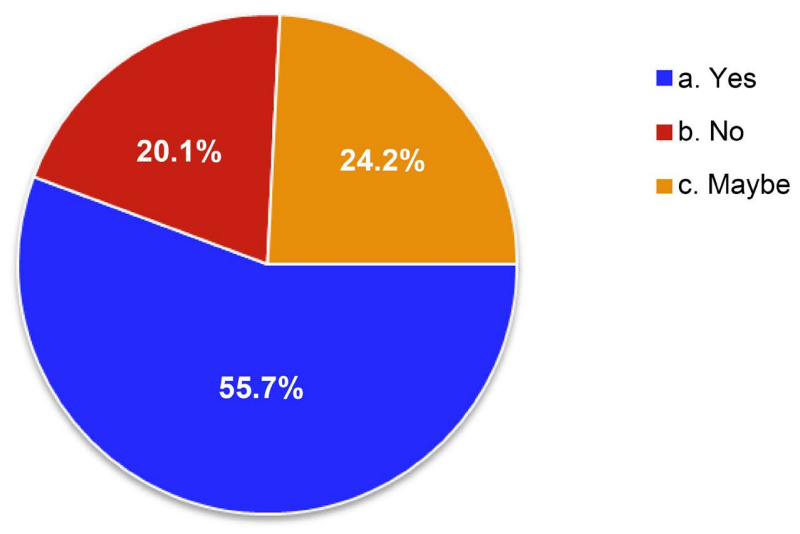

Figure 5. Egyptian consumers' fear of the future. Source: Data are from author himself.

The main changes in consumer behavior, according to survey responses (Figure 5 ), was spending more time at home (approximately $62 \%$ of the sample) which resulted in increased home activities such as Internet use, subscription to television channels, home hobbies, cooking, and more home deliveries; while streets were empty and use of cars and gas was increasingly declining.

An evident behavior change, on which $48 \%$ of the sample agreed, is an increase in use of the internet and its associated activities, reflecting an individual's need for mental stimulus that keeps the mind active and functioning instead of surrendering to complete rest. It also reflects the importance, in the life of the modern human, of maintaining communication with the outside world and following news.

Among the most frequent items appearing in behavior change was also an increased interest in healthy lifestyles, which in turn had its effect on a decline in gatherings, celebrations and social visits; and an increase in the consumption of vitamins, tonics, detergents and disinfectants.

The following diagram shows the main areas of change in consumer behavior patterns resulting from Coronavirus pandemic (Figure 6).

\subsubsection{Impact of COVID-19 Pandemic on Spending Patterns of Egyptian Families}

The degree by which Egyptian family incomes were affected by the pandemic varied greatly. For some families, the income has decreased dramatically, such as those working in restaurants, cafes or tourism sectors, while for others the income has increased, such as workers in the health sector; scientific laboratories; and sales of medicine, detergents and disinfectants, but the majority of people changed their consumption patterns.

In the study conducted by the researcher, results indicate that about $50 \%$ of the sample members had decreased incomes due to the pandemic, while $48 \%$ were not affected, leaving a very small percentage whose incomes increased due to the pandemic. The vast majority of the sample agreed that their families changed their way of spending due to the pandemic, with more than $87 \%$ of the sample stating that their families' spending changed significantly (about 65\%) 


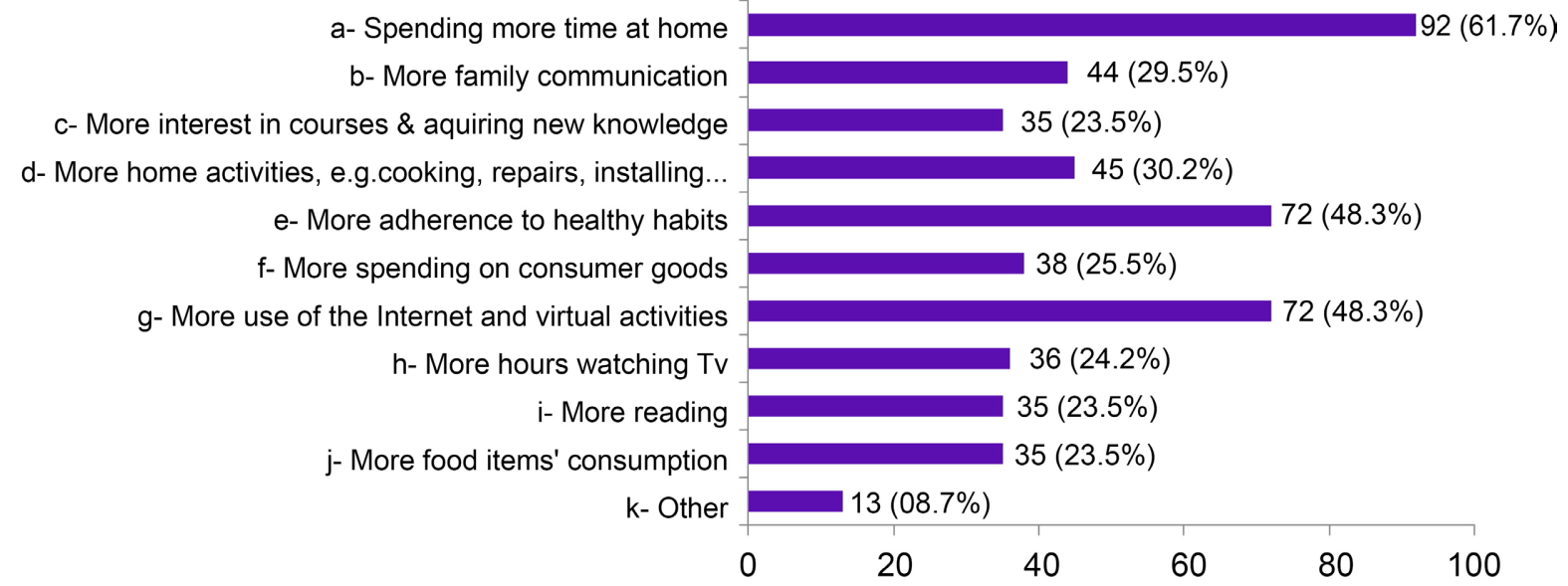

Figure 6. Consumer behavior pattern changes due to Coronavirus pandemic. Source: Data are from author himself.

following the pandemic while about $13 \%$ stating that it changed to some extent (Figure 7).

Most of the respondents (about 78\%) (Figure 7) agreed that their consumption patterns have changed due to COVID-19 pandemic and that their purchasing behavior has changed. More than $65 \%$ stated that their spending items changed by more than $75 \%$.

\subsubsection{Emergence of New Needs during the Pandemic Period}

The COVID-19 pandemic period helped the researcher to a great degree in stabilizing several factors surrounding the sample members and in reducing variances of external factors affecting consumer decisions. The majority of the sample respondents agreed on having spent a long time at home and on changing their consumption behavior patterns by replacing items in place of others. New needs have emerged, driving them to spend in different aspects (Figure 8).

\subsubsection{Conclusion}

Analysis of the sample's consumption patterns shows the following:

1) Consumer spending on physiological needs decreased in inverse proportion to income levels, which conforms with the study of Ward and Lasen (2009).

2) Demand for disinfectants and virus protection commodities such as vitamins and minerals-which can be classified as goods that satisfy safety needshas exceeded demand for goods that satisfy physiological needs to a large extent, which reflects the increased need for safety in times of disasters and crises. This is consistent with studies proposing that needs may overlap or change order as circumstances change. Although some studies deduced from people's hitting the streets to shop in times of epidemics that pursuit of physiological needs exceeded their sense of fear, this study proves, through the survey, that about $63 \%$ avoided going out to the markets and made do with only the basic needs in order to evade exposure to risks of disease by going to the markets.

3) The majority of respondents in the sample agreed that Internet use has increased on the work-level and for home entertainment. 


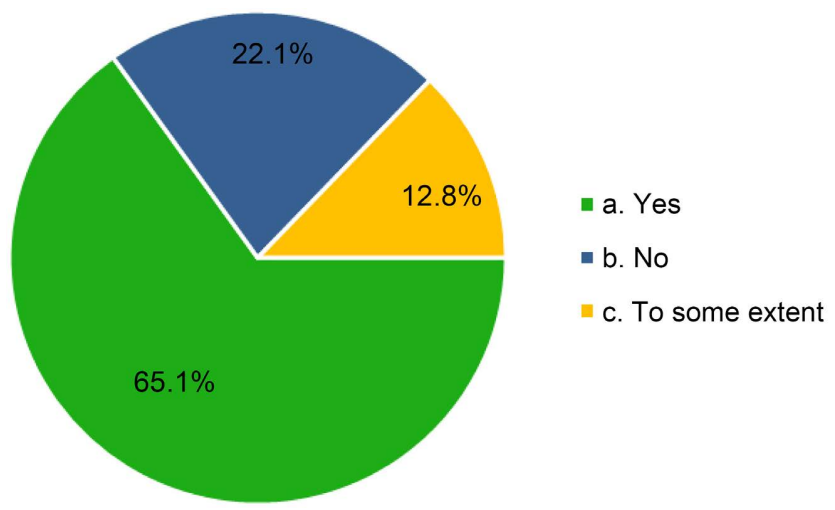

Figure 7. Change in Egyptian family spending due to COVID-19 pandemic. Source: Data are from author himself.

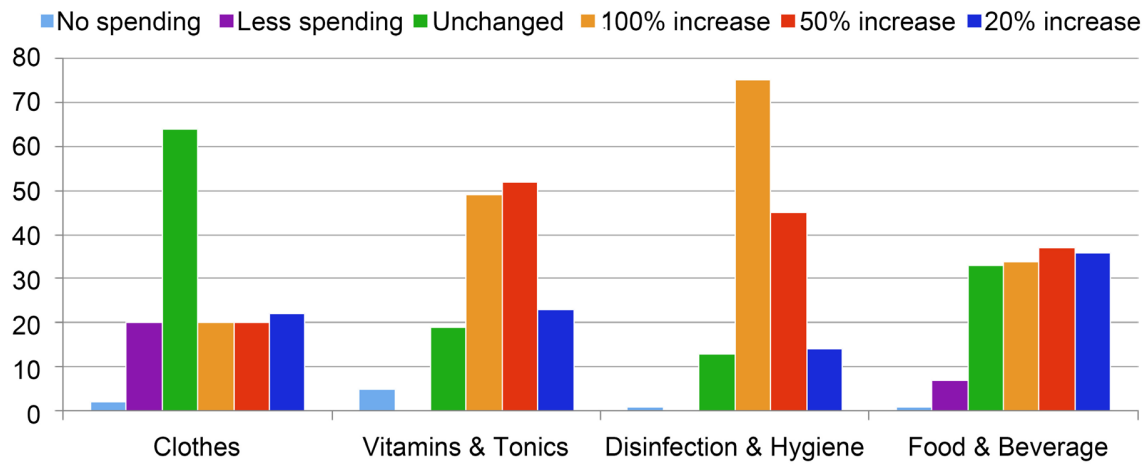

Figure 8. Change in spending on items by item categories due to COVID-19 pandemic. Source: Data are from author himself.

4) A new trend has emerged in buying patterns regarding an increase in demand for entertainment goods and activities such as TV platforms, movies and Internet games, observed in all categories in the sample, all age groups and income levels, and whether residents of the capital Cairo or outside it.

The researcher thus proposes addition of a ninth level in Maslow's hierarchy of needs: the need for entertainment and happiness. The researcher sees that this need has in effect driven producers in the various epochs to produce a myriad of goods and services that attempt to satisfy this need, starting from arenas holding fights between man and animal, to the appearance of cinema, radio and television; and lately computer and video games. Producers have tried to satisfy this desire in various ways. It is distinct from aesthetic needs, since what satisfies the need for entertainment may not necessarily be beautiful. It is also distinct from learning or self-actualization needs, as what is entertaining may have zero learning value and nothing to do with developing the self. Similarly, entertainment may not lead to transcendence. Entertainment is a human need in itself and has been known since the dawn of time and will continue to exist until the end of time (Figure 9).

5) The survey's collected data indicate that household spending items during the COVID-19 pandemic can be arranged starting with physiological needs then 


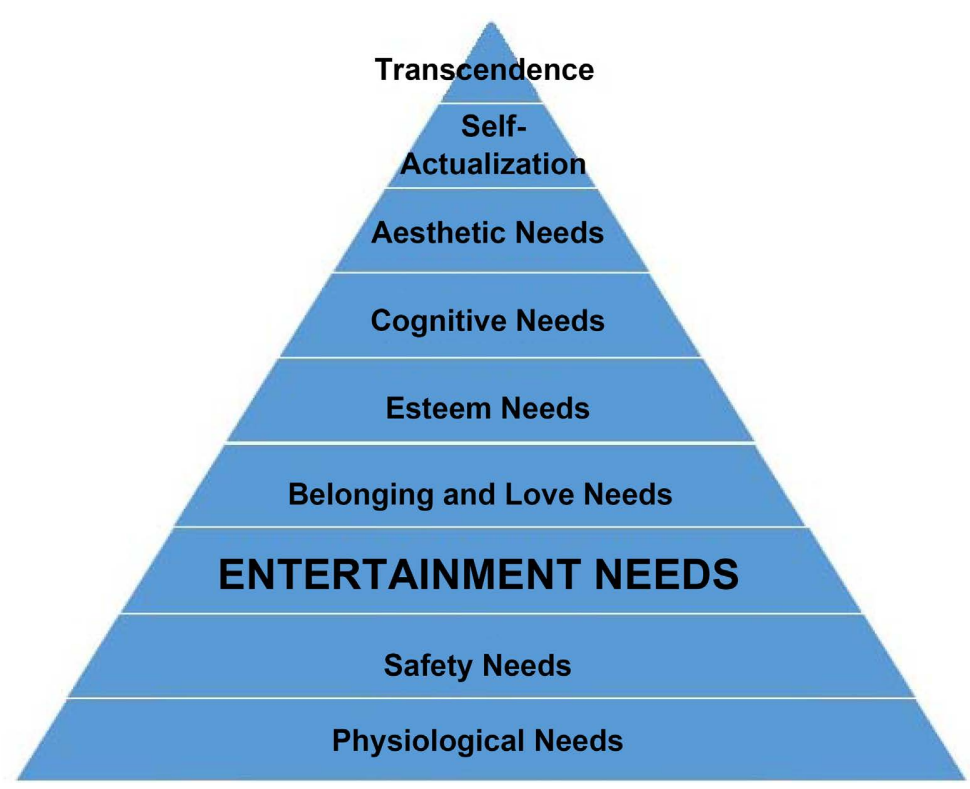

Figure 9. A level of "Entertainment Needs" proposed to be added to Maslow's hierarchy of needs. Source: Data are from author himself.

safety needs in the form of disinfectants, detergents and vitamins/tonics; then followed Internet subscription packages. By asking the sample members about their main Internet uses, they stated work and study as the major uses, then following the news and watching YouTube videos, and finally subscribing to movie platforms, which confirms the emergence of the entertainment need as a fundamental need, that comes directly after the safety need in importance.

\subsection{The Relationship between Demographic Variables and the Egyptian Society}

This section in the study aims to analyze the relationship between a number of demographic variables for 376 sample members of the Egyptian society, residing in and outside the capital of Cairo, and a number of variables that represent the differences that have occurred in the lifestyle of Egyptians due to the Coronavirus pandemic. Statistical analysis of this sample includes:

1) Statistical analysis of the relation between age and the changes in Egyptians' lifestyle due to COVID-19 pandemic in the form of spending on various commodities (food, transportation, medicine, clothes and goods from the Internet, etc.) as well as anxiety about the future;

2) Statistical analysis of the relation between income and the changes in Egyptians' lifestyle due to COVID-19 pandemic in the form of spending on various commodities (food, transportation, medicine, clothes and goods from the Internet, etc.) as well as anxiety about the future;

3) Significance of gender differences regarding the changes in Egyptians' lifestyle due to COVID-19 pandemic in the form of spending on various commodities (food, transportation, medicine, clothes and goods from the Internet, etc.) as well as anxiety about the future; 
4) Significance of differences between residents of Greater Cairo and residents of other regions outside of it regarding changes in Egyptians' lifestyle due to COVID-19 pandemic in the form of spending on various commodities (food, transportation, medicine, clothes and goods from the Internet, etc.) as well as anxiety about the future;

5) Whether the work sector has been affected in general by the variables representing the changes in Egyptians' lifestyle due to COVID-19 pandemic in the form of spending on various commodities (food, transportation, medicine, clothes and goods from the Internet, etc.) as well as anxiety about the future.

The following sections present the statistical analysis ${ }^{2}$

1) Statistical analysis for the relation between age and variables of change in lifestyle and spending on various commodities (food, transportation, medicine, clothes and goods from the Internet, etc.) and the relation between age and anxiety about the future (Table 1).

From this analysis (Table 1), we conclude that:

a) There is a significant relation between age and changed behaviors due to

Table 1. The relation between age and variables of change in lifestyle and spending on various commodities (food, transportation, medicine, clothes and goods from the Internet, etc.) as well as the relation between age and anxiety about the future.

\begin{tabular}{llcc}
\hline & & \multicolumn{2}{c}{ Age } \\
\cline { 3 - 4 } $\mathrm{N}$ & \multicolumn{1}{c}{ Relation between age and... } & $\begin{array}{c}\text { Spearman } \\
\text { Correlation } \\
\text { Coefficient }\end{array}$ & Sig \\
\hline 1 Change in behavior & 0.283 & 0.000 \\
2 & Change in spending mode & 0.185 & 0.025 \\
3 Direction of change in spending mode & 0.060 & 0.471 \\
4 Spending on food and beverages & -0.202 & 0.014 \\
5 Spending on disinfection and hygiene & -0.151 & 0.067 \\
6 Spending on vitamins & -0.239 & 0.003 \\
7 Spending on clothes & -0.014 & 0.865 \\
8 & Spending on transportation & -0.079 & 0.342 \\
9 & Internet shopping & 0.132 & 0.109 \\
10 & Number of items started or increased buying via Internet & 0.237 & 0.004 \\
11 Anxiety about the future & 0.034 & 0.680 \\
12 Changes in work pattern & 0.099 & 0.229 \\
13 Change in income & -0.060 & 0.466 \\
\hline
\end{tabular}

Source: Data are from author himself.

${ }^{2} \mathrm{Sig}$ is the level of significance; it makes the correlation coefficient significant only if it is less than 0.05. Likewise, in T-tests of independent samples, the presence of significant differences between variables according to gender (male or female) or residence (in Greater Cairo or outside it) is if the level of significance is less than 0.05 . 
COVID-19 pandemic, significant with a very high degree of confidence (99\%) and in direct proportion, which indicates that the elderly were the most affected with the greatest behavior change due to the pandemic. It is natural for older people to have more awareness and knowledge than the younger ones, and to be the most aware of the importance and seriousness of the pandemic and the need to take all precautionary measures.

b) There is a significant relation between age and change of spending style or mode due to COVID-19 pandemic, significant with a high degree of confidence (95\%) and in direct proportion, which indicates that older people were the most affected with the greatest change in spending mode during the COVID-19 pandemic.

c) There is a significant relation between age and spending on food and beverage due to COVID-19 pandemic, significant with a high degree of confidence (95\%) and in inverse proportion, which indicates that youths were the most affected with the greatest change in spending on food and beverages due to the pandemic. This is a logically sound result since most youths, students and fresh graduates, prefer coffee shop and restaurant food, and with the high risk of food not prepared at home as well as the lockdown and curfew, the group most affected by change in spending on food and drinks outside the homes was the most affected for this item. Spending on food and beverage especially was reduced for this group.

d) There is a significant relation between age and spending on vitamins due to COVID-19 pandemic, significant with a very high degree of confidence (99\%) and in inverse proportion, which indicates that youths are spending more on vitamins during the pandemic. A possible explanation is that the younger generation prefers to use vitamins than other medicines in case of being infected, in addition to their interest in vitamins and minerals and tonics to improve their general health and build muscle.

e) There is a significant relation between age and the change in behavior as related to Internet shopping due to COVID-19 pandemic. It is significant with a very high degree of confidence (99\%) and in direct proportion, which indicates that older people have shifted to Internet shopping more than younger ones, a logical result of their staying at home more than youths, even without the pandemic. Studies also indicate that they are at higher risk of Coronavirus than youths, a further reason for increasing their keeping to their homes. An additional explanation for their increased online shopping is their relatively higher incomes than the younger groups.

2) Statistical analysis for the relation between income and spending on various commodities (food, transportation, medicine, clothes and goods from the Internet, etc.) as well as the relation between income and anxiety about the future (Table 2).

From this analysis (Table 2), we conclude that:

a) There is a significant relation between income and change in spending on food and beverages, with a $95 \%$ degree of confidence in inverse proportion, as 
Table 2. The relation between income and spending on various commodities (food, transportation, medicine, clothes and goods from the Internet, etc.) as well as the relation between income and anxiety about the future.

\begin{tabular}{|c|c|c|c|}
\hline \multirow[b]{2}{*}{$\mathrm{N}$} & \multirow[b]{2}{*}{ Relation between income and spending and... } & \multicolumn{2}{|c|}{ Income } \\
\hline & & $\begin{array}{l}\text { Spearman } \\
\text { Correlation } \\
\text { Coefficient }\end{array}$ & Sig \\
\hline 1 & Change in behavior & 0.126 & 0.126 \\
\hline 2 & Change in spending mode & 0.048 & 0.562 \\
\hline 3 & Direction of change in spending mode & -0.030 & 0.720 \\
\hline 4 & Spending on food and beverages, water & -0.180 & 0.028 \\
\hline 5 & Spending on disinfection and hygiene & -0.067 & 0.417 \\
\hline 6 & Spending on vitamins & -0.080 & 0.333 \\
\hline 7 & Spending on clothes & -0.132 & 0.111 \\
\hline 8 & Spending on transportation & -0.166 & 0.043 \\
\hline 9 & Internet shopping & 0.119 & 0.148 \\
\hline 10 & Number of items started or increased buying via Internet & 0.249 & 0.002 \\
\hline & Anxiety about the future & -0.088 & 0.288 \\
\hline 12 & Changes in work pattern & -0.033 & 0.693 \\
\hline 13 & Change in income & 0.041 & 0.620 \\
\hline
\end{tabular}

Source: Data are from author himself.

higher income people have been spending less on food and drink than those with lower income during COVID-19 pandemic. This is quite logical since lower-income people, under normal circumstances, appropriate expenses for food and drink with no frills, no margin for luxuries, hence no significant change due to the pandemic since they were spending on the bare essentials to start with.

Conversely, high-income people lowered their spending on food for two reasons:

- Spending on restaurant food was cut down due to the lockdown and curfew imposed by the government,

- Spending on food bought from restaurants was cut down due to fear of non-compliance with precautionary procedures and hygiene, relying more on drinks and food prepared at home.

b) There is a significant relation between income and change in spending on transportation, with a $95 \%$ degree of confidence in inverse proportion, as higher income people lowered their spending on transportation during COVID-19 pandemic more than those with lower incomes, a logical result of greater spending on trips and excursions under normal circumstances among high-income than low-income people.

3) Significance of gender differences concerning spending on various commodities (food, transportation, medicine, clothes and goods from the Internet, etc.) during COVID-19 pandemic and the significance of gender differences as related to anxiety about the future 
Table 3. Gender differences concerning spending on various commodities (food, transportation, medicine, clothes and goods from the Internet, etc.) during COVID-19 pandemic and as related to anxiety about the future.

\begin{tabular}{rlcc}
\hline $\mathrm{N}$ & \multicolumn{3}{c}{ Gender difference in relation to... } \\
\cline { 2 - 4 } & & T statistic & Sig \\
\hline 1 & Change in behavior & 2.908 & 0.004 \\
2 & Change in spending mode & 2.479 & 0.014 \\
3 & Direction of change in spending mode & -0.143 & 0.886 \\
4 & Spending on food and beverages & -0.768 & 0.444 \\
5 & Spending on disinfection and hygiene & -1.264 & 0.208 \\
6 & Spending on vitamins & -0.415 & 0.678 \\
7 & Spending on clothes & -1.106 & 0.271 \\
8 & Spending on transportation & -1.487 & 0.139 \\
9 & Internet shopping & 0.350 & 0.727 \\
10 & Number of items started or increased buying via Internet & 2.299 & 0.023 \\
11 & Anxiety about the future & -0.061 & 0.951 \\
12 & Changes in work pattern & 2.560 & 0.011 \\
13 & Change in income & -2.294 & 0.023 \\
\hline
\end{tabular}

Source: Data are from author himself.

This is the result of a difference test (T-test) between means of two independent samples (Table 3):

From this analysis (Table 3), we conclude that:

a) There are significant differences by gender as regards change of habits, with a $99 \%$ degree of confidence.

b) There are significant differences by gender as regards change in spending, with a $95 \%$ degree of confidence.

c) There are significant differences by gender as regards the number of items the consumer started or increased buying via Internet, with a $95 \%$ degree of confidence.

d) There are significant differences by gender as regards the work pattern, with a $95 \%$ degree of confidence, a result that can be explained by the fact that the governemental lockdown regulations differed for females than males, where mothers of children from birth to 12 years old were allowed fully paid leaves throughout the year since the outbreak of the Coronavirus, in addition to other factors and decrees that represented an obvious dissimilarity in work pattern changes between males and females.

e) There are significant differences by gender as regards change in income, with a $95 \%$ degree of confidence. This also can be explained by the lockdown decrees, which locked down sectors whose employees are mostly females, such as day nurseries to count just one example. Thus incomes could be affected for one gender (whether males or females) more than the other.

4) Significance of differences between residents in Greater Cairo and 
residents outside the capital as related to spending on various commodities during COVID-19 pandemic and the significance of such differences concerning anxiety about the future

This is the result of a difference test (T-test) between means of two independent samples (Table 4):

From this analysis (Table 4), we conclude that:

There are no significant differences between residents of Greater Cairo and those living elsewhere in any of the variables measuring change in lifestyle due to COVID-19 pandemic, an indication of the close similarity of reaction by all Egyptians in and outside the capital toward the change in all aspects of spending as well as anxiety toward the future due to the start of the Coronavirus pandemic.

Table 4. Differences between residents in Greater Cairo and residents outside the capital as related to spending on various commodities during COVID-19 pandemic and the significance of such differences concerning anxiety about the future.

\begin{tabular}{|c|c|c|c|}
\hline \multirow[t]{2}{*}{$\mathrm{N}$} & \multicolumn{3}{|c|}{$\begin{array}{l}\text { Difference between Cairo residents, residents outside Cairo, } \\
\text { and those living abroad, in relation to... }\end{array}$} \\
\hline & & T statistic & Sig \\
\hline 1 & Change in behavior & -0.411 & 0.681 \\
\hline 2 & Change in spending mode & -1.547 & 0.124 \\
\hline 3 & Direction of change in spending mode & 0.800 & 0.425 \\
\hline 4 & Spending on food and beverages & 0.629 & 0.53 \\
\hline 5 & Spending on disinfection and hygiene & -0.912 & 0.363 \\
\hline 6 & Spending on vitamins & 1.685 & 0.094 \\
\hline 7 & Spending on clothes & -1.143 & 0.255 \\
\hline 8 & Spending on transportation & 0.044 & 0.965 \\
\hline 9 & Internet shopping & -0.147 & 0.883 \\
\hline 10 & Number of items started or increased buying via Internet & -0.378 & 0.706 \\
\hline 11 & Anxiety about the future & -0.152 & 0.879 \\
\hline 12 & Changes in work pattern & -0.072 & 0.943 \\
\hline 13 & Change in income & 1.158 & 0.249 \\
\hline
\end{tabular}

Source: Data are from author himself.

Table 5. The relation between the work sectors and each of the variables measuring the change in lifestyle due to COVID-19 pandemic.

\begin{tabular}{|c|c|c|c|}
\hline \multirow[b]{2}{*}{$\mathrm{N}$} & \multirow[b]{2}{*}{ Relation between the work sector and... } & \multicolumn{2}{|c|}{ Work Sector } \\
\hline & & $\begin{array}{c}\text { Spearman } \\
\text { Correlation } \\
\text { Coefficient }\end{array}$ & Sig \\
\hline 1 & Change in behavior & -0.018 & 0.831 \\
\hline 2 & Change in spending mode & -0.241 & 0.003 \\
\hline
\end{tabular}




\begin{tabular}{|c|c|c|c|}
\hline \multicolumn{4}{|c|}{ Continued } \\
\hline 3 & Direction of change in spending mode & -0.159 & 0.054 \\
\hline 4 & Spending on food and beverages & -0.03 & 0.72 \\
\hline 5 & Spending on disinfection and hygiene & 0.072 & 0.386 \\
\hline 6 & Spending on vitamins & 0.037 & 0.657 \\
\hline 7 & Spending on clothes & 0.048 & 0.566 \\
\hline 8 & Spending on transportation & -0.102 & 0.218 \\
\hline 9 & Internet shopping & 0.025 & 0.761 \\
\hline 10 & Number of items started or increased buying via Internet & -0.015 & 0.857 \\
\hline 11 & Anxiety about the future & -0.227 & 0.006 \\
\hline 12 & Changes in work pattern & -0.06 & 0.472 \\
\hline 13 & Change in income & 0.035 & 0.675 \\
\hline
\end{tabular}

Source: Data are from author himself.

No governorate exhibited any significant changes either less or more than the remaining governorates.

5) Significance of the relation between the work sectors and each of the variables measuring the change in lifestyle due to COVID-19 pandemic (Table 5).

From this analysis (Table 5), we conclude that:

There is a significant relation between the work sector for the sample and only two variables:

a) Change in spending mode,

b) Anxiety about the future.

This indicates that some work sectors were fundamentally and significantly affected by the change in spending, a logical result considering that the work sector is the main source of income for spending for the majority of Egypt's population.

Also, the future for the majority of Egyptians is determined foremost by the work sector, thus the significant relation between the work sector and anxiety about the future during the lockdown imposed by COVID-19 pandemic for many months is also a logical result.

\section{General Results and Recommendations}

1) Emergence of new consumer needs calls for further study. This includes the need for electronic transactions and applications and the need for entertainment, which creates new markets for companies and manufacturers.

2) The change in behavior patterns and spending modes, as shown in this research, points marketers toward new directions in marketing methods. For example, the increase in using the Internet can be further exploited by marketers in marketing their various goods via the Internet, more than traditional marketing methods.

3) The increase in Internet shopping has developed an inexpensive parallel 
market for displaying and marketing goods. Some establishments may prefer to focus on goods directed to older consumer groups, while others choose to increase marketing efforts for younger consumers as a promising market that has not been fully exploited yet.

4) The Coronavirus pandemic created a feeling of anxiety about the future among numerous groups. This could inspire insurance firms to develop new programs tailored to the issues caused by the Coronavirus pandemic and similar crises.

\section{In light of these results, we recommend the following.}

\section{Firstly, at the level of theory:}

The researcher recommends a revision of Maslow's hierarchy of needs through an analytical study on diverse consumer samples with the aim of exploring the possibility of modifying this hierarchy to conform with the world's progress, variables and pressures, which may lead to the need to add one or more new levels to it or change their order.

\section{Secondly, at the level of application:}

The researcher recommends that production and marketing institutions revise their work policies and approaches in light of the particular findings of this study:

- The increasing importance of electronic marketing

- Flexibility in movement among priorities for satisfying needs in light of changes in income or societal phenomena

- Increased worry and anxiety among the elderly during social disasters

- A growing demand for a number of entertainment services and commodities

- A growing tendency to work from home

- The increasing spread of distance learning.

\section{Conflicts of Interest}

The author declares no conflicts of interest regarding the publication of this paper.

\section{References}

\section{Arabic References}

Abdulhameed, M. R. (2020, July 7). Effect of the Coronavirus on Egyptian and Global Economies. The Arab Democratic Center Site. (Original: عبد الحميد، محمد رزق

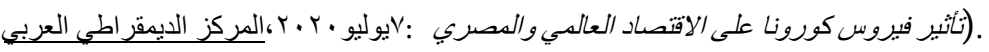

OECD (2020, October). Response to Covid-19 Crisis in the Middle East and North Africa. Organization for Economic Co-Operation and Development.

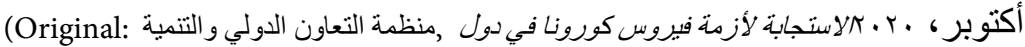
(الشرق الأوسط وشمال إفريقيا.

\section{English References}

Accenture (2020, April). How COVID-19 Will Permanently Change Consumer Behavior. Accenture.

Alderfer, C. P. (1971). Effect of Individual, Group, and Intergroup Relations on Attitudes 
toward a Management Development Program. Journal of Applied Psychology, 55, 302-311. https://doi.org/10.1037/h0031536

Allport, G. (1937). The Functional Autonomy of Motives. American Journal of Psychology, 50, 151-156. https://doi.org/10.2307/1416626

http://psychclassics.yorku.ca/Allport/autonomy.htm

Allport, G. (1961). Pattern and Growth in Personality. Holt, Rinehart and Winston.

Funakoshi, M., \& Hartman, T. (2020, March 23). Mad March: How the Stock Market Is being Hit by COVID-19. World Economic Forum.

Gentilini, U., Almenfi, M., Dale, P., Blomquist, J., Palacios, R., Desai, V., \& Moreira, V. (2020, May 15). Social Protection and Jobs Responses to COVID-19: A Real-Time Review of Country Measures ("Living Paper" Version). World Bank.

Herzberg, F. (1966). Work and the Nature of Man. World Publishing Company.

James, W. (1890). Chapter 10. The Consciousness of Self. In The Principles of Psychology (Vol. 1, pp. 145-203). Henry Holt and Company.

Kotishwar, A. (2020). Impact of Covid-19 Pandemic on Stock Market with Reference to Select Countries-A Study. Academy of Accounting and Financial Studies Journal, 24, 1-9.

Kotler, P., \& Keller, K. (2006). Marketing Management (12th ed.). Pearson Prentice Hall.

Lowry, R., \& Maslow, B. G. (1979). The Journals of A. H. Maslow. Thomson Brooks/Cole.

Maslow, A. H. (1943). A Theory of Human Motivation. Psychological Review, 50, 370-396. https://doi.org/10.1037/h0054346

Maslow, A. H. (1970a). Motivation and Personality. Harper \& Row Publishers.

Maslow, A. H. (1970b). Religions, Values, and Peak Experiences. Penguin. (Original Work Published 1966).

McLeod, S. A. (2020, December 29). Maslow's Hierarchy of Needs. Simply Psychology. http://www.simplypsychology.org/maslow.html

Puttaiah, M. H., Ravekar, A. K., \& Avramakis, E. (2020, December 10). All Change: How COVID-19 Is Transforming Consumer Behaviour. Swiss Re Institute.

Revich, A. (2005). The Three Fundamental Needs Model. http://www.workitout.ca/

Thompson, S. K. (2012). Sampling (3rd ed.). John Wiley. https://doi.org/10.1002/9781118162934

Ward, D., \& Lasen, M. (2009, January 31). An Overview of Needs Theories behind Consumerism. European School of Economics, MPRA, Munich Persona, REPEC ARCHIVE. 